\title{
Atypical epithelial changes in the uterine cervix ${ }^{1}$
}

\author{
JAMES A. KIR KLAND \\ From the Department of Pathology, Queen's College (University of St. Andrews), Dundee
}

SYNOPSIS Atypical epithelium, i.e., epithelium showing changes just insufficient to warrant $\vec{a}$ diagnosis of carcinoma in situ, was re-studied in surgical material from 66 patients. Most of these specimens had originally been reported as suspicious or potentially malignant. Of the 66 patients, 62 were alive and 46 of these were 'untreated' having had no treatment to the cervix since the् original operation.

Thirty-seven of the 66 were examined personally, 28 of these being 'untreated'; nineteen werev found to have gynaecological abnormalities. Cytological examination was performed on 36, with only one suspicious smear; none of these patients was found to have invasive carcinoma or carcinomao in situ. Of the remaining 25 patients not seen personally, all were considered by their doctors to be free of any significant cervical lesion.

The incidence of progression from atypical epithelium to carcinoma in situ is so different in the published reports that the definitions must surely be different. Sections from 15 cases of carcinoma? in situ were therefore submitted to seven skilled pathologists, and as only 70 out of 105 diagnoses? came into this category, the need for agreed definition is obvious.

The present study shows a depressing persistence of the original or similar complaint. The followup (average 7.4 years) suggests that atypical epithelial change is unlikely to progress to carcinoma

The technique of exfoliative cytology has shown that abnormal cells are shed from certain lesions of the uterine cervix and are invisible to the unaided eye of the gynaecologist. These are early invasive carcinoma, carcinoma in situ, and the possibly premalignant lesions described by such terms as epithelial anaplasia, epithelial dysplasia, atypical epithelium, unquiet epithelium, or even undifferentiated regenerating epithelium. While early invasive carcinoma and carcinoma in situ have been the subject of many publications, there are few reports on the diagnosis, implications, and treatment of these lesser epithelial abnormalities.

Atypical epithelial changes are frequently encountered in routine gynaecological and pathological practice and give rise to considerable diagnostic and prognostic difficulty. In recent years it has been suggested that anything from $4 \%$ to $65 \%$ of these atypical epithelial changes precede or progress untreated to carcinoma in situ (McKay, Terjanian, Poschyachinda, Younge, and Hertig, 1959; Saphir, Leventhal, and Kline, 1959; Foraker and Reagan, 1956). The purpose of this study was to seek objective Received for publication 30 October 1962

${ }^{1}$ Part of an M.D. thesis submitted to the University of St. Andrews. 'Present address: Department of Obstetrics and Gynaecology, Queen Elizabeth Hospital, Woodville, South Australia. histological criteria of non-malignancy, indeed of 'non-premalignancy', and to test these findings against the results of a follow-up study of 66 patients with these possibly premalignant changes in the uterine cervix.

\section{DEFINITION OF ATYPICAL EPITHELIUM}

The term 'atypical epithelium' is used in this paper to describe changes in the cervical epithelium whichô differ from the normal but do not satisfy the criteria for a diagnosis of carcinoma in situ. The histologicap picture varies from a proliferation of the basal cells to a superficial and more active proliferation oftern. accompanied by irregularity and moderate crowding of the component nuclei (Figs. 1 and 2). Even when there is considerable nuclear irregularity, the changes 0 seldom involve the full thickness of the epithelium and the cytoplasmic borders are retained, whereaso in carcinoma in situ the full thickness of the epio thelium is involved and little or no cytoplasm can be seen. The nuclei are not as hyperchromatic as in? carcinoma in situ, and mitoses, although occasionallyo frequent, are always normal.

None the less it is sometimes extremely difficule to distinguish an extreme degree of an atypica epithelium from carcinoma in situ, and for many, ao 


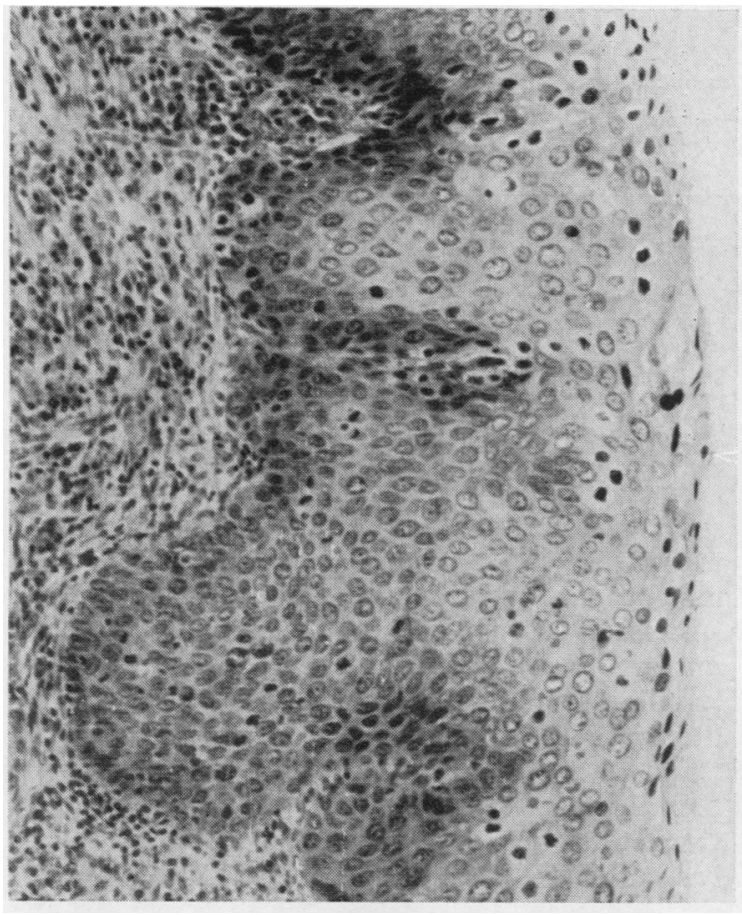

FIG. 1. Severe basal-cell hyperplasia with numerous mitoses, some of which are situated superficially. Nuclei are moderately crowded. Haematoxylin and eosin $\times 125$.

distinction between these two lesions has become a matter of opinion rather than a clear-cut diagnosis.

\section{MATERIALS AND METHODS}

After reviewing 4,337 cervical biopsies obtained in this region between the years 1948 and 1958, I selected a group of 74 patients with a biopsy either originally reported as suspicious of malignancy or regarded on re-survey as suspicious or atypical. The vagueness of the boundaries in this group is, in part, a reflection of our current uncertainty, but it was intended thereby to include all the cases in which the microscopic diagnosis lacked precision. Of these 74 selected patients, 66 were traced.

The 66 original biopsy specimens consisted of 57 cervical biopsies, eight amputated cervices, and one complete uterus and cervix. The original pathology reports gave 13 as potentially malignant, 50 as suspicious, and three as negative for malignancy. On the basis of these original reports a repeat biopsy had been performed on 15 patients and a further five patients had a cervical biopsy, uterine curettage, or hysterectomy on other clinical grounds.

Of the 66 patients traced, 62 are alive, four having died of a disease unrelated to the cervix (one of carcinoma of the ovary, two of acute leukaemia, one of Hodgkin's disease). Excluding those patients who had been subjected to repeat biopsies of hysterectomy, we are left

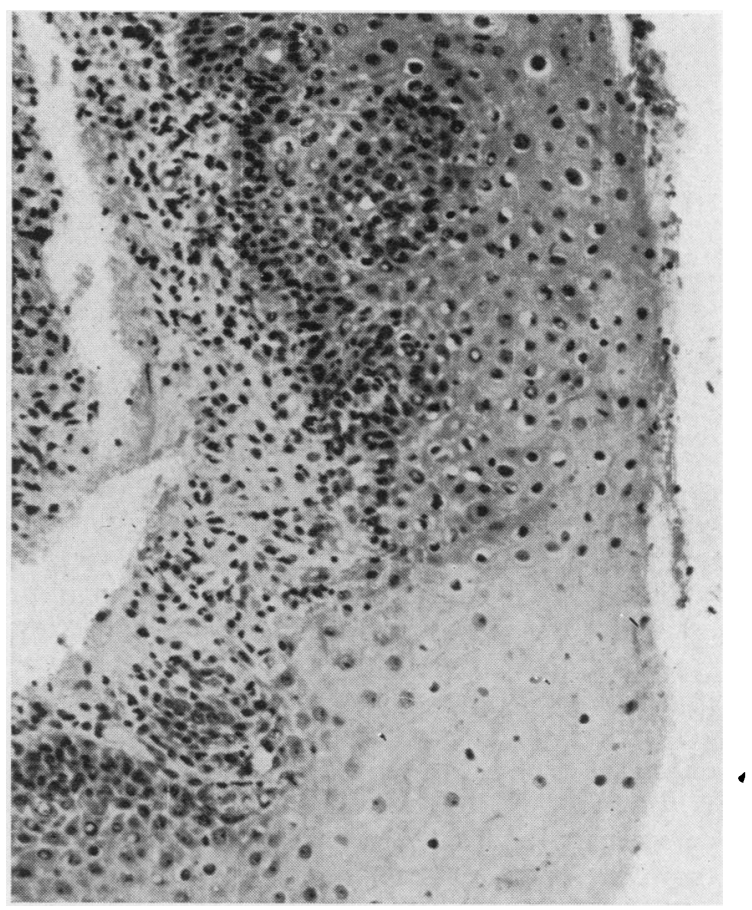

FIG. 2. A sharp transition between normal epithelium and irregular atypical epithelium. Haematoxylin and eosin $\times$ 125.

with 46 of the 62 surviving patients who had experienced no further interference with the cervix since the original biopsy and were considered to have been 'untreated'.

In cooperation with Professor J. Walker, of the Department of Obstetrics and Gynaecology of the University of St. Andrews, arrangements were made for the examination of the 62 surviving patients. Thirty-seven patients attended and were seen personally, and of these 28 were 'untreated' since the original biopsy. Twenty-five patients either refused to attend or had left the district, but a report on their condition was received from the respective general practitioners; 18 of these patients were 'untreated'.

The duration of follow-up is shown in Table I. The minimum period was three years and the maximum 12 years with an average of 7.4 years for the whole group

TABLE I

\begin{tabular}{|c|c|c|c|c|c|c|c|c|c|c|}
\hline & & DUI & TIC & ol & FOI & ow & & & & \\
\hline & 3 & 4 & 5 & 6 & 7 & 8 & 9 & 10 & 11 & 12 \\
\hline $\begin{array}{lr}\text { Treated } & 16 \\
\text { Untreated } & 46 \\
\text { Total } & 62\end{array}$ & 1 & $\begin{array}{l}1 \\
6\end{array}$ & $\begin{array}{l}3 \\
4\end{array}$ & $\begin{array}{l}2 \\
7\end{array}$ & $\begin{array}{l}1 \\
7\end{array}$ & $\begin{array}{l}5 \\
5\end{array}$ & $\begin{array}{l}1 \\
7\end{array}$ & $\begin{array}{l}2 \\
3\end{array}$ & $\overline{2}$ & $\overline{5}$ \\
\hline $\begin{array}{l}\text { Seen personall } \\
\text { Treated } 99 \\
\text { Untreated } 28\end{array}$ & 1 & $\overline{2}$ & $\begin{array}{l}3 \\
3\end{array}$ & $\begin{array}{l}2 \\
7\end{array}$ & $\overline{6}$ & $\frac{3}{-}$ & 4 & - & 2 & 4 \\
\hline
\end{tabular}


TABLE II

RESULTS OF CLINICAL EXAMINATION AND CYTOLOGICAL GRADING

\begin{tabular}{|c|c|c|c|c|c|c|c|}
\hline \multirow[t]{2}{*}{ No Cervical Abnormality } & \multirow[t]{2}{*}{ Chronic Cervicitis } & \multirow[t]{2}{*}{ Vulvitis, Vaginitis } & \multirow[t]{2}{*}{ Menorrhagia } & \multicolumn{4}{|c|}{ Cytological Grading } \\
\hline & & & & $I$ & II & III & IV \\
\hline 18 & 6 & 10 & 2 & 21 & 14 & 1 & $\mathbf{0}$ \\
\hline
\end{tabular}

of patients and an average of $\mathbf{7 . 6}$ years for the patients personally examined.

\section{RESULTS}

CLINICAL EXAMINATION Nineteen of the 37 patients who attended had various gynaecological abnormalities (Table II). These included 16 with chronic vaginal discharge usually associated with chronic cervicitis, two with menorrhagia, and one with stress incontinence. This high incidence of persisting gynaecological disorder was a depressing discovery, and not least that most of them still had the condition for which the original treatment was given. It would seem that many women are prepared to endure for years considerable genital discomfort if they have once been 'treated'. This problem will be considered again later.

A cytological examination was performed in 36 patients (Table II). All but one had a completely negative smear, and the exception was regarded as suspicious only. Fourteen smears were classified as group II (Papanicolaou) because of evidence of severe inflammation which could not be regarded as a 'normal' state.

On the basis of this subsequent clinical and cytological examination a further biopsy was performed on five patients: two had a hysterectomy for menorrhagia, one a laparotomy and biopsy of cervix for dyspareunia, and one an anterior colporrhaphy for stress incontinence. Five further patients were referred to the routine out-patient clinics or their general practitioner, and pessary treatment was recommended for the chronic vaginal or cervical inflammation. Hysterectomy has been recommended to one other patient.

Of the five patients from whom cervical biopsies had been taken, two showed persisting basal-cell hyperplasia and one of those subjected to hysterectomy persisting nuclear atypia. The remaining patients had no significant cervical abnormality on clinical, cytological, or histological examination. None of these patients was found to have carcinoma in situ or invasive carcinoma.

A report was received regarding the condition of each of the remaining 25 patients, 18 of whom were 'untreated'. All were considered, by their doctor, to be free of any significant cervical lesion.
DISCUSSION

The histological appearances of the cervix commonly $\vec{P}$ regarded in the past as suspicious of malignancy are $\vec{\omega}$ possibly better understood than they were, but thereo is no doubt that the appearances in these biopsies can? still cause considerable diagnostic difficulty for thepathologist, particularly if he is unaware of the wide range of benign cervical epithelial abnormalities.

It seems clear now that cytology can detect theo presence of carcinoma that can be missed by biopsy, 을 but there is an increasing danger that, influenced by the cytological report, some pathologists may be tempted to give a diagnosis of carcinoma in situ or premalignancy to what in fact is atypical epithelium. ${ }^{-}$ Overdiagnosis of malignancy (Park and Lees, 1950) $\vec{\circ}$ has a distorting effect on the accuracy of rates of cure, and in face of the insistence of the cytologist the histopathologist must surely strive for an objectives diagnosis before studying the clinical or other information (Park, 1956).

The frequency of atypical epithelium progressing to carcinoma in situ is very variously reported. With the more aberrant varieties, a progression to car $\frac{0}{3}$ cinoma in situ has been reported in up to $65 \%$ of cases(Galvin, Jones, and Te Linde, 1955). At the opposite end of the scale there is the report by McKay et al (1959) of four cases of carcinoma in situ and one case of invasive carcinoma occurring 13 months to nine years after a diagnosis of atypical hyperplasia had. been made in 129 patients, a progression rate of $3.8 \%$ 응

The less severe abnormalities, such as basal-celR hyperplasia and squamous metaplasia, do not seenf to have a significant relationship to carcinoma in situs or invasive carcinoma, although Galvin et al. (1955) did report progression from basal-cell hyperplasia to carcinoma in situ in two cases out of 93. While these reports suggest that increasing degrees of epitheliab irregularity have a greater tendency to progress, this was not confirmed by Koss and Durfee (1961), whe found that microscopically innocuous 'borderline' lesions could be followed by invasive carcinomad while 'aggressive-looking' lesions might disappear?

The variations in the rates of progression of atypical epithelium to carcinoma in situ and of carcinoma in situ to invasive carcinoma may be due to variations in the histological diagnosis of these various lesions. As an investigation of this possibilityo 


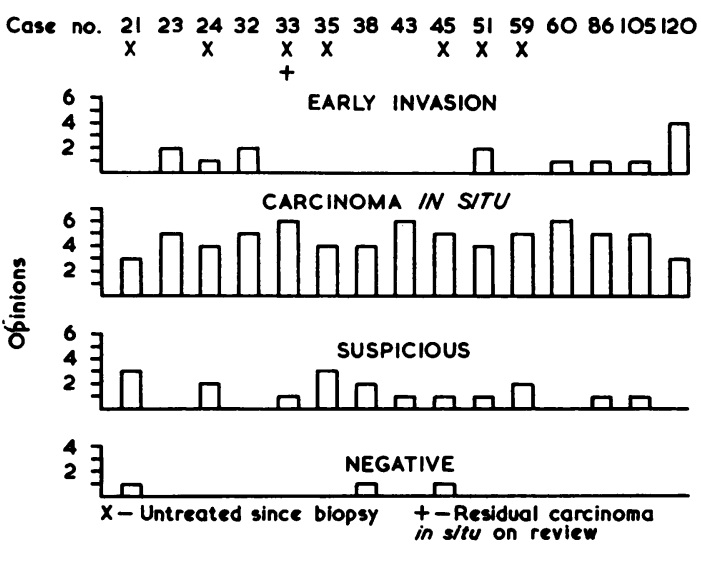

FIG. 3. Histological diagnosis in 15 cases of probable carcinoma in situ.

a selected group of 15 cases of probable carcinoma in situ was submitted for opinion to seven histopathologists from both Britain and abroad (Fig. 3). All of the pathologists concerned had considerable histological experience, the most junior having had six years of routine diagnostic experience, and the majority many more. Opinions on the same section from certain cases could vary from benign squamous metaplasia to frank invasive carcinoma although the majority of opinions favoured a diagnosis of carcinoma in situ in every case. Histological features in the slides that gave rise to the widest variation in diagnosis were extensive squamous metaplasia associated with infection and nuclear irregularities, atypical epithelium with a fragmented basal layer, and the perennial problem of tangential sectioning of acutely inflamed epithelium. There is surely no doubt that all the observers knew that inflammation may cause severe nuclear irregularity, and yet to judge by the diagnoses, this was apparently responsible for much diagnostic variation.

In this selected group of 15 cases, $20 \%$ of the opinions were not in favour of a diagnosis of carcinoma in situ or invasive carcinoma, whereas $13.3 \%$ of the opinions were in favour of early invasion. The overall agreement of only $66.6 \%$ in favour of a diagnosis of carcinoma in situ is disturbing and suggests that a source of reference and arbitration such as a national panel is required in order that a clearer understanding be obtained of the diagnostic features and significance of carcinoma in situ.

When more disputable cases are considered there is an even wider scatter of opinions. An international investigation of this diagnostic variation was recently carried out by Norden (1961) who visited many centres in western Europe and obtained

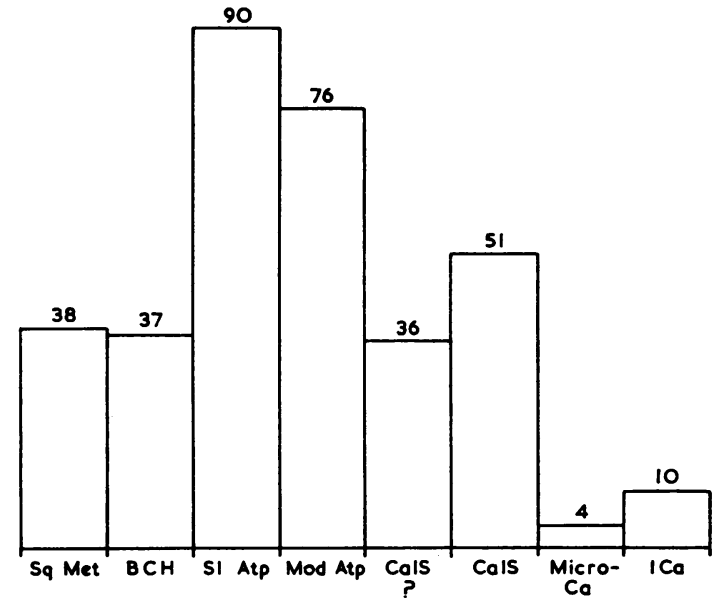

FIG. 4. Histological opinion in nine cases of probable atypical epithelium.

opinions on a set of nine cases of probable atypical epithelium (Fig. 4). This investigation also showed that the opinions on the same section could vary from benign squamous metaplasia to invasive carcinoma even when the majority were not in favour of a diagnosis of malignancy. The wide variation in opinion in such cases again reinforces the desirability of better diagnostic criteria and the urgent need to correlate these appearances with the clinical outcome in a large series of cases.

All but three of the 66 patients in this series were thought originally to have cervical epithelial changes which were suspicious or potentially malignant, and in fact in four cases had been regarded as diagnostic of malignancy. The appearances in the cervical biopsies from these four patients, only one of whom had a subsequent hysterectomy, are what would now be called atypical epithelium. None of the 66 patients in this series has developed carcinoma in situ or invasive carcinoma of the cervix. The conclusion seems inescapable: that atypical epithelial changes of the uterine cervix are, over a period of three to 12 years, unlikely to progress either to carcinoma in situ or frank carcinoma. While this statement can only be made with confidence about 28 'untreated' patients examined personally, it is substantiated in considerable measure by the remaining 'untreated' patients who were seen by their general practitioner.

Persistence of inflammation of the genital tract despite previous treatment appears to be common. Sixteen of 37 patients in this series had either a chronic cervicitis or vaginitis and over $50 \%$ (19 out of 37 ) had some gynaecological abnormality sufficiently severe to warrant further therapy in 14 patients. The high level of persistence, despite 
previous therapy, is disturbing and must give rise to doubts about the efficacy of cautery (and biopsy) of the cervix as a treatment for chronic cervicitis. More happily, these findings suggest that there is little, if any, short-term relationship between chronic inflammation of the cervix with its associated epithelial abnormalities and carcinoma of the cervix.

From the practical point of view, a less pessimistic attitude would seem to be justified, at least if the present series of patients can be considered representative. In cases in which there remains considerable doubt about the histological appearances, even after full clinical investigation, a conservative approach seems reasonable and would justify the adoption of less drastic treatment. In young women, repeated cytological examination is all that is required, although simple hysterectomy may be employed for patients past the menopause or fo those who do not desire further children.

I wish to thank the British Empire Cancer Campaign for a research grant, the Council of Europe for a medicaf fellowship, and Professor A. C. Lendrum for reading the script. I am particularly grateful to Professor James Walker for his constant encouragement and help.

\section{REFERENCES}

Foraker, A. G., and Reagan, J. W. (1956). Cancer (Philad.), 9, 470 ? Galvin, G. A., Jones, H. W., and Te Linde, R. W. (1955). Amero J. Obstet. Gynec., 70, 808.

Koss, L. G., and Durfee, G. R. (1961). Diagnostic Cytology and its. Histopathologic Bases, Ch. 8. Pitman Medical, London.

McKay, D. G., Terjanian, B., Poschyachinda, D., Younge, P. A. and Hertig, A. T. (1959). Obstet. and Gynec., 13, 2.

Norden, J. G. (1961). Personal communication.

Park, W. W. (1956). Lancet, 1, 701.

, and Lees, J. C. (1950). Arch. Path., 49, 73. Path., 32, 446.

\section{Broadsheets prepared by the Association of Clinical Pathologists}

The following broadsheets (new series) are published by the Association of Clinical Pathologists. They may be obtaine from Dr. R. B. H. Tierney, Pathological Laboratory, Boutport Street, Barnstaple, N. Devon. The prices include postage. but airmail will be charged extra.

3 The Detection of Barbiturates in Blood, Cerebrospinal Fluid, Urine, and Stomach Contents. 1953. L. C. NICKOLLS. 1s.

4 The Estimation of Carbon Monoxide in Blood. 1953. D. A. STANLEY. $1 \mathrm{~s}$.

5 The Identification of Reducing Substances in Urine by Partition Chromatography on Paper. 1953. G. B. MANNING. $1 \mathrm{~s}$.

6 The Paul-Bunnell Test. 1954. R. H. A. SWain. 15.

7 The Papanicolaou Technique for the Detection of Malignant Cells in Sputum. 1955. F. HAMPSON. 1s.

13 The Identification of Serotypes of Escherichia coli Associated with Infantile Gastro-enteritis. 1956. JOAN TAYLOR. $1 \mathrm{~s}$.

14 The Determination of Serum Iron and Serum Unsaturated Iron-binding Capacity. 1956. ARTHUR JORDAN. 1s.

16 Preservation of Pathological Museum Specimens. 1957. L. W. PROGER. 1s.

17 Cultural Diagnosis of Whooping-cough. 1957. B. W. LACEY. $1 \mathrm{~s}$.

18 The Rose-Waaler Test. 1957. C. L. GREenBuRY. $1 \mathrm{~s}$.

20 Investigation of Porphyrin/Porphyria. 1958 (reprinted 1962). C. RIMINGTON. 2s.

23 The Dried Disc Technique for Bacterial Sensitivity Tests. 1959. R. W. FAIRBROTHER and J. C. SHERRIS. 1s.

24 Safe Handling of Radioactive Tissues in the Laboratory and Post-mortem Room. 1959. R. C. CURRAN. 1s.

26 The Periodic Acid-Schiff Reaction. 1959. A. G. E. PEARSE $1 \mathrm{~s}$.

28 Daily Fatty Acid Excretion. 1960. A. C. FRAZER. 2s.

29 The Preparation of Bone for Diagnostic Histology. 1960. D. H. COLLINS. 2 s.
30 Control of Accuracy in Chemical Pathology. 196L G. H. GRANT. 4s.

31 Investigation of Haemorrhagic States with Specia Reference to Defects of Coagulation of the Bloow 1961. E. K. BLACKBURN. 4s.

32 Detection of Resistance to Streptomycin, P.A.S., an $\$$ Isoniazid in Tubercle Bacilli. 1961. R. CRUICK SHANK and S. M. STEWART. 2s.

33 The Laboratory Detection of Abnormal Haemos globins. 1961. H. LEHMANN and J. A. M. AGERE़ 4s.

34 Titration of Antistreptolysin O. 1961. H. GOODE? and R. E. O. WILLIAMs. $2 s$.

35 The Estimation of Faecal 'Urobilinogen'. 196\%. C. H. GRAY. 2s.

36 Quantitative Determination of Porphobilinogen an Porphyrins in Urine and Faeces. 1961. c. RIMINGTON 3s. 6 d.

37 The Paper Electrophoresis of Serum and Urinar Proteins. 1961. G. FRANGLEN and N. H. MARTIN. 4s.

38 The Augmented Histamine Gastric Function Tesit 1961. M. LUBRAN. 2s.

39 Investigation of Haemolytic Anaemia. 1961. J. . SELWYN. $2 s$.

40 Short Term Preservation of Bacterial Culturé 1962. E. Joan Stokes. 2s.

41 Serological Tests for Syphilis. 1962. A. E. wiLkiN" SON. 6 s.

42 The Determination of Glucose 6-Phosphate Deho drogenase in Red Cells. 1962. T. A. J. PRANKERP 2s.

43 Mycological Techniques. 1962. R. W. RIDDELל 3s. 6d. 